\title{
Mobilidade do Aeroporto Internacional Governador Aluízio Alves
}

\section{Mobility of Governador Aluízio Alves International Airport}

\author{
Thaiana Coelho Monteiro Fernandes \\ Universidade Federal do Rio Grande do Norte - UFRN - Brasil \\ thaicoelho@hotmail.com \\ ORCID: 0000-0002-4000-2348 \\ Maria Valéria Pereira de Araújo \\ Universidade Federal do Rio Grande do Norte - UFRN - Brasil \\ valeriaaraujoufrn@gmail.com \\ ORCID: 0000-0002-8072-0387 \\ Andréa do Nascimento Barbosa Cacho \\ Universidade Federal do Rio Grande do Norte - UFRN - Brasil \\ deiacacho@gmail.com \\ ORCID: 0000-0001-7003-9785 \\ Iranilton Marcolino Pereira \\ Universidade Federal do Rio Grande do Norte - UFRN - Brasil \\ iraniltonmarcolino3@gmail.com \\ ORCID: 0000-0003-0110-2765 \\ Maria Isabel de Medeiros Brito \\ Universidade Federal do Rio Grande do Norte - UFRN - Brasil \\ belmedeiros@gmail.com \\ ORCID: 0000-0003-0737-3582
}

Submetido em 02/12/2017; Aprovado em 09/09/2018

\section{Resumo}

O caso para ensino Mobilidade do Aeroporto Internacional Governador Aluízio Alves apresenta uma situação de decisão relacionada ao problema de mobilidade dos passageiros e turistas no percurso para o aeroporto. O Secretário de Turismo de São Gonçalo do Amarante, juntamente com os gestores dos municípios da região metropolitana de Natal estão enfrentando desafios relacionados ao conflito existente entre a definição dos papéis e atribuições de serviços de transportes oferecidos no terminal: o transporte público e o privado (as vans fretadas, os receptivos turísticos, os táxis e os serviços de transporte particular). Destaca ainda os problemas de infraestrutura de mobilidade para a utilização dos serviços de transporte ao aeroporto, relacionados a: condições e manutenção das estradas, sinalização, custos da mobilidade, qualidade dos serviços oferecidos pelas empresas de transporte e tempo da logística de transporte de passageiros. Os dados secundários para o desenvolvimento do caso foram extraídos de jornais, livros e sites, enquanto os primários foram obtidos através de entrevistas. 0 caso pode ser aplicado nas turmas de graduação e pós-graduação de administração, turismo e gestão pública, nas seguintes disciplinas: teoria geral da administração; logística; turismo organização e dinâmica; sistemas de transportes e desenvolvimento urbano e regional.

Palavras-chave: Mobilidade; Acesso ao aeroporto; Transportes; Infraestrutura.

\begin{abstract}
The teaching case for Mobility at Governador Aluízio Alves International Airport presents a decision making situation related to the problem of passenger and tourism mobility on the way to the airport. The Tourism Secretary of São Gonçalo do Amarante and also all the secretaries of the metropolitan region of Natal are facing challenges related to the definition of roles and attributions of transport services offered at the airport terminal: public and private transportation (chartered vans, tourist receptions, taxis and Uber). It also highlights the problems of mobility infrastructure for the use of
\end{abstract}


transport services to the airport, related to: conditions and maintenance of roads, signs, mobility costs, quality of services offered by transport companies and time of passenger transport logistics. The secondary data for the development of the case were extracted from newspapers, books and websites, while the primary data were obtained through interviews. The case may be applied in undergraduate and postgraduate courses in management, tourism and public management in the following disciplines: general management theory; logistics; tourism organization and dynamics; transport systems and urban and regional development.

Key-words: Mobility; Airport Access; Transports; Infraestructure.

\section{Introdução}

Em 31 de maio de 2014, de forma a atender os passageiros que chegaram à capital do Estado do Rio Grande do Norte para assistir aos jogos da Copa da FIFA 2014, foi oficialmente inaugurado o Aeroporto Internacional Governador Aluízio Alves, também conhecido como Aeroporto de São Gonçalo do Amarante, por estar localizado na cidade do mesmo nome, que veio substituir o antigo terminal aeroportuário, Aeroporto Augusto Severo.

O Aeroporto Aluizio Alves tem 40 mil metros quadrados de área construída e capacidade para atender até seis milhões de passageiros por ano (Inframérica, 2017). 0 terminal oferece 45 balcões de check-in e 10 quiosques de autoatendimento para o embarque de passageiros. São cinco esteiras de restituição de bagagens destinadas ao tráfego doméstico e internacional. 0 estacionamento tem capacidade inicial para 850 veículos.

0 terminal é administrado pelo Consórcio Inframérica, formado pelo grupo Engevix e Corporación América, o qual investiu 480 milhões de reais e tem direito a 28 anos de concessão. Apesar de o novo aeroporto oferecer inúmeros diferenciais relacionado à infraestrutura física e, principalmente, extensa área para expansão seja na questão de fluxo de passageiros, seja na ampliação dos negócios, a sua construção gerou inúmeras polêmicas.

Uma delas está relacionada à logística de transporte de passageiros, pois o aeroporto está situado a 24 quilômetros do centro de Natal e a 36 quilômetros da Praia de Ponta Negra (principal zona hoteleira da capital potiguar). A cidade de Natal possui segundo dados da Pesquisa de Serviços de Hospedagem do IBGE (2011) 11.692 unidades habitacionais (UH's), totalizando 19.532 leitos. Saindo de Ponta Negra, o tempo do deslocamento que antes era feito em 20 minutos passou para 1 hora e 10 minutos, em média, a depender do trânsito da região norte da cidade. A partir de então, a população local passou a tomar consciência das dificuldades em relação ao trajeto ao novo terminal, principalmente, devido às vias de acesso ao novo aeroporto serem precárias e os serviços de transporte público da cidade e região metropolitana não atender satisfatoriamente aos residentes.

Em meio a tantas polêmicas que envolve o Aeroporto Aluísio Alves, o Secretário de Turismo de São Gonçalo do Amarante, juntamente com os gestores públicos dos municípios da região metropolitana de Natal, estão enfrentando desafios relacionados à mobilidade de acesso ao terminal, e conflitos relativos aos serviços de transporte oferecidos aos passageiros e à população local.

\section{Acesso ao aeroporto}

0 terminal aeroportuário Aluizio Alves possui três acessos principais: 1) 0 Acesso Norte, com distância de 47,6 Km e duração média de tempo de 1h 03 minutos, através da Ponte Newton Navarro, passando pelos bairros da zona leste e norte da cidade; 2) 0 Acesso Centro, com distância de 24,5 Km e duração média de tempo de 40 minutos, passando pela ponte de Igapó, cruzando bairros da região oeste e norte; 3) 0 Acesso Sul, com distância de $21 \mathrm{Km}$ e duração média de tempo de 30 minutos, inaugurado em julho de 2018, passando pelos municípios de Parnamirim, Macaíba e São Gonçalo. A principal dificuldade dos acessos norte e centro, estão relacionados ao tráfego intenso, já que ambos cruzam a zona mais populosa da capital potiguar.

Enquanto que o acesso sul, por sua vez, possui problemas de sinalização e iluminação, apesar de ter sido pensado para se tornar a principal via de acesso à zona sul e ao litoral sul da cidade, além de área de escoamento de cargas do terminal aeroportuário para as rodovias do país.

Apesar das várias opções de acesso, a localização do novo aeroporto tem gerado desconforto aos passageiros que utilizam os serviços aéreos em decorrência da mobilidade urbana geral da cidade. 


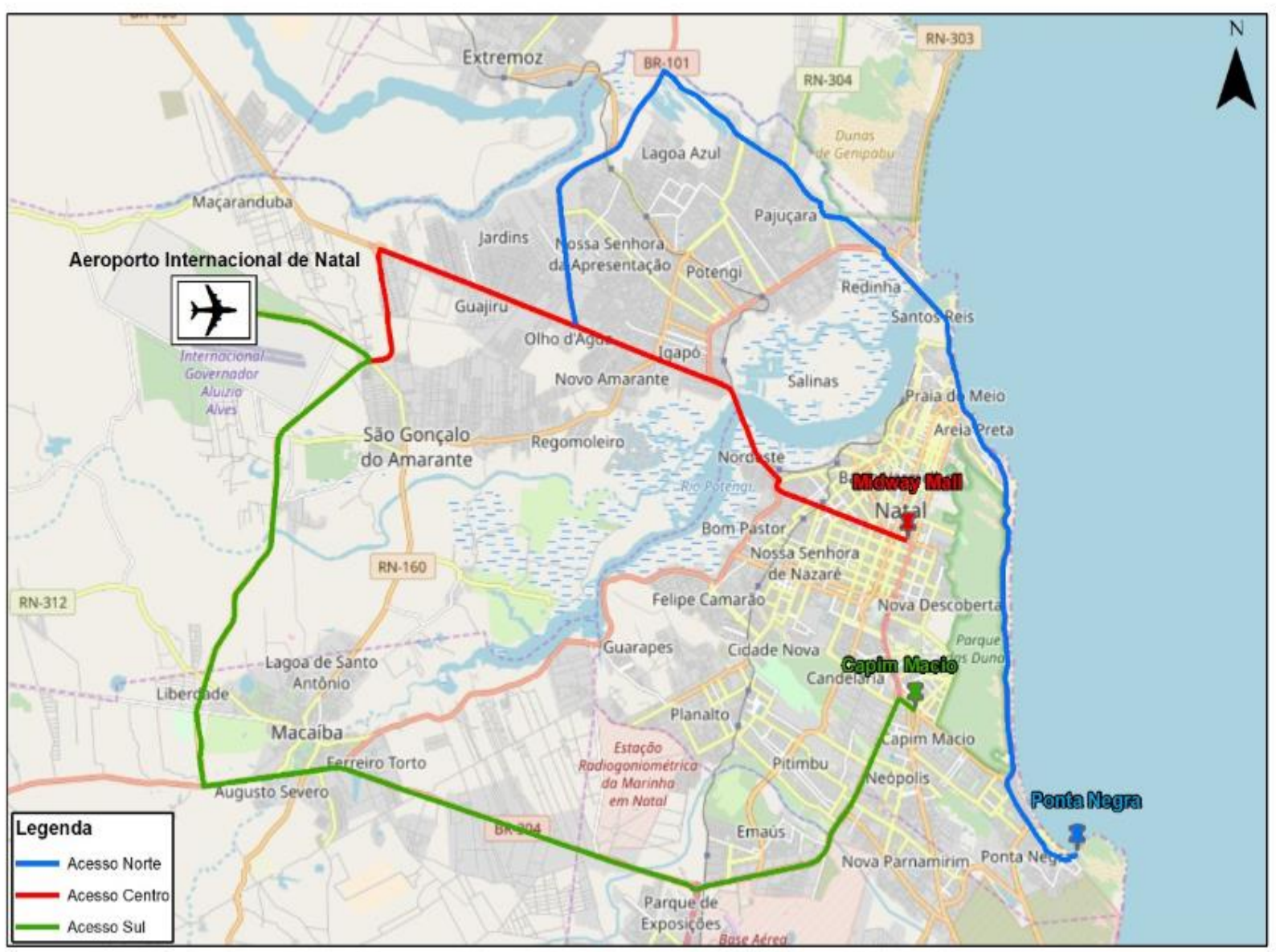

Figura 1- Acessos ao Aeroporto Aluisio Alves Fonte: Open Street Map, Natal, 2018.

Outras dificuldades no acesso ao aeroporto relacionam-se: a existência de apenas uma linha de ônibus, com parte de trecho em estrada carroçável; de deficiências na sinalização onde circulam os ônibus urbanos e à falta de padronização de abrigos de passageiros, ao longo do itinerário dos ônibus que levam até o aeroporto, como por exemplo: Av. Salgado Filho, Av. Bernardo Vieira, Av. Tomaz Landim e BR- 101 norte e sul.

\section{Transporte para o aeroporto}

A empresa responsável pelo serviço público de transporte do aeroporto é a Trampolim da Vitória, esta tem como propósito, o serviço de transporte coletivo intermunicipal de passageiros entre a capital potiguar e as cidades de Parnamirim, Macaíba e São Gonçalo do Amarante.

Das 19 linhas oferecidas, apenas uma, a "R", faz o trajeto para o aeroporto. Trata-se de ônibus de linha regular, sem local apropriado para acomodar a bagagem. 0 percurso da linha inclui a circulação nos bairros periféricos da zona oeste e norte de Natal, bem como do município de São Gonçalo do Amarante. 0 trajeto realizado pelo ônibus dura, em média, $1 \mathrm{~h}$ e 10 minutos, com custo no valor de $\mathrm{R} \$$ 4,20 , permitindo aos passageiros (residentes e turistas) acessarem duas paradas principais da capital, a rodoviária de Natal - Terminal Rodoviário Severino Tomaz da Silveira e o Shopping Midway. Apesar de relevantes, esses pontos são distantes da principal zona turística da cidade, a praia de Ponta Negra. 0 que significa que para quem precisa se deslocar até lá, necessariamente tem que realizar baldeação em algum ponto do itinerário da linha R.

\section{Conflitos na mobilidade: táxi, van, transferistas, receptivos e serviço de transporte particular}

0 problema da logística da mobilidade urbana em torno do Aeroporto Internacional Governador Aluízio Alves no transporte de passageiros envolve a disputa entre taxis, vans ("transferistas"), receptivos e serviço de transporte particular, ainda mais, pelas limitações do transporte público e da legislação em vigor relacionada à operação de transporte de passageiros no aeroporto. 
Jornais locais noticiaram em 2016 e 2017 alguns incidentes envolvendo motoristas de transporte particular de passageiros, taxistas, DER e Polícia Rodoviária Estadual (O Natalense, 2016; AgoraRN, 2016, Tribuna do Norte, 2017; NovoNotícias, 2017). As reportagens trouxeram à tona as agressões sofridas pelos motoristas do Uber no trajeto até o aeroporto Aluísio Alves e tentativas do DER e PM-RN de impedir o trabalho dos motoristas do Uber. 0 fato gerou indignação com os usuários/passageiros que utilizam os serviços do aplicativo, uma vez que a escolha do passageiro está pautada na relação custobenefício. Diante do dilema, o Diretor do Demutran informou que enquanto órgão fiscalizador de trânsito do município, só tem como coibir a ação do Uber nas dependências do aeroporto.

Na visão do empresário do ramo de receptivo turístico, George Costa, o problema é a falta de regulamentação no que tange aos serviços das vans, ou seja, rota e preço para o serviço oferecido aos passageiros. Para o empresário, ocorre no aeroporto uma confusão entre os serviços de van e táxis. Pois de acordo com a legislação vigente, as vans turísticas só podem transportar passageiros que tenham adquirido o serviço antecipadamente na origem, sendo transportados de ou para terminais de embarque turísticos, e para estabelecimentos de acomodação (hotéis, pousadas, albergues e etc).

Diante do exposto, o empresário levantou o seguinte problema: "as empresas que estão operando no aeroporto são regulamentadas para fazer o transporte turístico e o transporte turístico inclui o transporte do aeroporto para os hotéis, e dos hotéis para o aeroporto ou para estação de passageiros. Mas elas não podem fazer serviços de transporte para as residências e isso vem acontecendo". Para ele, isso ocorre por falta de regulamentação daquela atividade de venda.

$\mathrm{Na}$ visão do empresário, o setor tem uma regulamentação, mas faz outro tipo de serviço clandestinamente. Ele levantou dois problemas com a operação das vans no aeroporto: o modo lotação e o transporte de passageiros nas residências. O serviço domiciliar de transporte é um serviço de responsabilidade do táxi e não do receptivo.

Para George, "o serviço de receptivo está sendo desvirtuado na medida em que não existe uma coordenação dos serviços de transporte oferecidos pelo aeroporto". Falta, na visão do empresário, uma licitação pública para que empresas especializadas em transporte passem a oferecer o serviço de forma regular sem afetar os já existentes, táxis e receptivos.

0 diretor do Demutran diz ter dificuldade, porque essas questões relativas aos serviços das vans turísticas são de responsabilidade do Ministério do Turismo (MTur), que é representado localmente pela Emprotur e quem autoriza a circulação do veículo é o DER. "Então, você tem aí duas instituições que estão envolvidas num só serviço". Outra questão levantada por Paulo Macedo é a questão da origem do serviço: "nasce dentro do município de São Gonçalo e se desloca muitas vezes para Natal. A gente tem dificuldade porque o que é permitido pela portaria do MTur é que eles podem fazer o translado quando o passageiro adquire o serviço antecipadamente".

O DER reforça a fiscalização para inibir o transporte clandestino no aeroporto. Em 30 de novembro de 2015, o programa jornalístico RN TV (InterTVCabugi) divulgou uma reportagem para falar sobre este assunto. Segundo a reportagem, para organizar o transporte de passageiros no aeroporto de São Gonçalo do Amarante, o DER está fiscalizando táxis e vans na saída do pedágio do aeroporto. Apenas quem é credenciado à cooperativa licenciada para prestar o serviço no local pode abordar os clientes.

João, taxista da COOPCON (Cooperativa dos Condutores de Táxi de São Gonçalo do Amarante) relata: "muita gente tem sofrido aqui com os transportes clandestinos de passageiros, e essa fiscalização vem tornar o nosso serviço melhor, para que o cliente não sofra constrangimento". Veículos não credenciados podem apenas deixar ou pegar passageiros, não sendo permitido fazer praça. Em teoria, ao serem parados pela fiscalização, os motoristas têm que apresentar algum comprovante de que o serviço foi agendado com antecedência.

De acordo com o depoimento do Diretor do DER, "o passageiro na cidade de origem manda uma mensagem de celular solicitando ao taxista que vá buscá-lo no aeroporto e coloca ali o RG dele. Quando ele chegar no pedágio, tem um posto avançado do DER, onde está instalada uma barraca branca. Ele apresenta ao fiscal o celular, provando que foi chamado pelo passageiro ainda na sua cidade de origem". Um taxista que não faz parte da frota credenciada do aeroporto veio de Pipa buscar uma passageira, mostrou o Voucher com o pedido da cliente e ficou satisfeito com a fiscalização. Ele disse: "Isso para nós é ótimo. Isso aumenta nosso serviço".

Na visão do diretor financeiro (e também ex-presidente) do Sindicato dos Taxistas, Aldemir Calixto, e do proprietário da Luck Receptivo a fiscalização do DER é muito falha e quase não existe. Calixto afirmou que "as vans que são contratadas pelas agências de viagem para levar turistas ao 
aeroporto também estão fazendo transporte de passageiro nos moldes dos taxis, oferecendo corrida no terminal, e cobrando valores mais baixos para atrair clientes".

Para o Diretor do Demutran, a prefeitura faz um trabalho de fiscalização de maneira precária porque a estrutura funcional é pequena. Em entrevista, o mesmo afirmou que o prefeito havia autorizado à contratação de agentes de trânsito temporário, até que se faça concurso. Em relação à fiscalização, Paulo Macedo disse que: "eu acredito que o município vai entrar com mais rigor nessa questão da fiscalização. 0 que nós precisamos é ter uma parceria com o Ministério do Turismo e com o DER, para que a gente possa trabalhar em conjunto. Porque a fiscalização não pode ser feita apenas pelo município, mas por todos os entes que estão envolvidos nesse processo.".

O serviço de fiscalização realizado pelos órgãos competentes visa proteger e garantir uma concorrência leal entre os diversos prestadores de serviço de transporte. Uma vez que a diferença entre o valor do táxi credenciado e do serviço das vans chega a ser cerca de $70 \%$. Por exemplo, o táxi cobra em média R \$ 100 para a região de Ponta Negra, localidade com maior número de Unidades Habitacionais - UH'S, enquanto as vans cobram por pessoa, em média, entre $\mathrm{R} \$ 30$ ou $\mathrm{R} \$ 40$. Caso haja duas pessoas, o valor cobrado é de $\mathrm{R} \$ 50$ e acima de seis pessoas, o valor cobrado cai significativamente em relação ao táxi, chegando a $\mathrm{R} \$ 20$ por pessoa. Apesar de o táxi oferecer mais conforto ao passageiro e o tempo de corrida ser reduzido em relação a van, muitos passageiros têm optado pelos serviços das vans. 0 motivo para o diretor do Demutran seria a presença marcante das empresas de receptivo que estão, de certa forma, em maioria na saída do saguão do passageiro, oferecendo seus serviços por preços menores.

Em uma tentativa de regularizar o serviço das vans, o DER visa limitar o serviço de transporte de vans apenas como receptivo turístico. Para George Costa, "foi criado um novo serviço". O serviço do receptivo não é serviço de transporte; receptivo tem a obrigatoriedade de fornecer um guia na van ou no ônibus".

Em suma, a ausência de regras para os prestadores de serviços de transporte no aeroporto tem gerado atritos entre os donos de receptivos, vans ("transferistas"), taxistas, Uber e passageiros. E, ainda sobre o assunto, o proprietário da Luck Receptivo é taxativo ao afirmar que "a ausência do poder público na organização e regulamentação do transporte de passageiros no aeroporto pode vir a desencadear problemas mais graves no futuro; quando se está dentro de um veículo de horário regular, transporte concedido por meio de uma licitação, você tem garantias estatais, o que não acontece quando o serviço não é regulamentado.".

Diante dos fatos, o Secretário de Turismo de São Gonçalo do Amarante, juntamente com os gestores dos municípios da região metropolitana de Natal deparam-se com esse grande desafio: o que pode ser feito para resolver os problemas relacionados a essa disputa? Como conduzir um processo de gestão de ações de mobilidade que atendam aos interesses públicos e da comunidade, garantindo os direitos dos cidadãos? 


\section{NOTA DE ENSINO}

\section{Fonte de dados}

Para a elaboração do caso, foram coletados dados secundários e primários a partir de publicações on-line, matérias de jornais e revistas, informações extraídas no site do aeroporto e empresas de transporte, e entrevistas. 0 nome das pessoas citadas no caso não foi alterado, uma vez que a publicação era de domínio público.

\section{Sugestões para discussão do caso}

O caso tem como objetivo gerar uma reflexão sobre as ações do secretário de turismo de São Gonçalo do Amarante, podendo desenvolver ações de políticas públicas que possam dar apoio à mobilidade urbana no deslocamento até o aeroporto, bem como efetuar atividades ou ações integradas com outros municípios, e demais stakeholders públicos e privados de apoio à mobilidade de passageiros que compõem a região metropolitana de Natal. Este caso pode ser lido em 40 min. na sala de aula e sugere-se a sua aplicação nas turmas de graduação em Turismo nas disciplinas de TGA (Teoria Geral da Administração), TOD (Turismo organização e dinâmica) e de Sistemas de Transportes; na graduação em Administração na turma de logística e TGA; e na graduação em Gestão Pública na disciplina de Desenvolvimento Urbano e Regional, TGA, Processo Decisório. Na pós-graduação pode ser aplicado em Logística, Turismo e Gestão Pública. Recomenda-se: 1) Leitura e brainwriting individual; 2) Brainstorming em grupo e consolidação das ideias individuais; 3) Brainstorming coletivo das ideias consolidadas e anotação do professor no quadro; 4) Discussão em plenária; 5) Tentativa de elencar quais ideias seriam prioritárias; 6) Possíveis planos de ação para solucionar o problema.

\section{Objetivos de aprendizagem}

Pretende-se desenvolver no aluno: 1) Reflexões sobre qual é o papel do gestor de turismo, com ênfase no desenvolvimento de políticas públicas de mobilidade para o município. 2) Identificar atribuições e papéis dos parceiros que constituem o turismo receptivo (transporte) juntamente aos taxistas credenciados ao aeroporto, para que não exista conflitos; 3) Diagnosticar, compreender e desenvolver alternativas para a solução de problemas. 4) discutir e identificar ações de logística aplicada a mobilidade e transporte de turista.

\section{Questões e análise do caso}

Para explorar a discussão do caso e o conhecimento do aluno em sala de aula, o professor poderá se apoiar na reflexão das seguintes questões, com respectivas sugestões de respostas para contribuir no desenvolvimento das competências dos discentes:

\section{1a) Quais os atores públicos envolvidos no problema do caso? Desenhe um mapa mental para melhor ilustrar sua resposta.}

As questões levantadas no caso refletem uma realidade não apenas local, mas nacional e quiçá mundial. Diversas cidades e regiões metropolitanas, no Brasil, passam por problemas similares. De um lado está o poder econômico impondo sua força no que diz respeito à expansão de negócios, do outro lado, a população local e o meio ambiente. 0 turismo enquanto fenômeno social e econômico exerce pressão em relação às infraestruturas necessárias para a expansão e manutenção da atividade na região.

0 problema levantado no caso envolve uma série de atores públicos e privados, pertencentes às três instâncias de governo (municipal, estadual e federal) mais atores privados: secretária de turismo de São Gonçalo, Consórcio Inframérica, Departamento de Estradas e Rodagens (DER), Governo do Estado do Rio Grande do Norte, Trade Turístico Local, Empresas de Transportes, Companhia Brasileira de Trens Urbanos (CBTU), taxistas e Uber. Em decorrência de o aeroporto estar situado nos limites geográficos do município de São Gonçalo do Amarante, cabe a esse município a responsabilidade sobre os serviços de transportes. Vasconcellos (2017) deixa claro que, a partir da constituição de 1988, a mobilidade urbana passa a ser um tema da alçada municipal.

A construção do mapa mental irá auxiliar os alunos a identificar a função de cada ator público e privado envolvidos no problema do caso.

2ª) Na sua opinião, qual o ponto em comum nas falas dos personagens envolvidos no caso? 
0 assunto tratado no caso, relacionado ao terminal aeroportuário inserido no contexto de uma região metropolitana, envolve tanto problemas relativos à logística de transporte quanto mobilidade urbana.

A mobilidade urbana, por sua vez, está relacionada à condição de deslocamento das pessoas dentro das cidades, ou seja, o trânsito de veículos e de pedestres, através do uso de transporte privado ou coletivo. De acordo com o Observatório das Metrópoles (2016), o Brasil é um dos países que mais sofre com problemas de mobilidade urbana, justamente por ter um histórico de planejamento urbano baseado no modelo rodoviário. Foi definido que o Brasil precisava ter um sistema rodoviário nacional e que, portanto, a partir da montagem desse sistema apoiado por alguns impostos de grande valor, assistimos um crescimento exponencial das rodovias e um desmantelamento lento e progressivo do sistema ferroviário (Vasconcelos, 2017). Como consequência dos investimentos realizados no modal rodoviário, os transportes públicos da maioria das cidades brasileiras são de má qualidade, o que incentiva o cidadão a buscar um meio de transporte particular.

0 crescimento das cidades, juntamente com o crescimento populacional, vem exigindo dos gestores públicos um olhar mais técnico no que diz respeito aos problemas da mobilidade urbana. Se deslocar dentro de uma municipalidade, entre bairros, é uma dificuldade comum nas cidades brasileiras. Isso está relacionado a problemas de integração entre os serviços de transportes e, na maioria dos casos, a dependência massiva de um único modal, o rodoviário.

Para Simon et al (2014), mobilidade nas cidades médias e grandes é uma questão contemporânea, não apenas em termos de facilidade nos deslocamentos, mas também, em termos de qualidade, nela incluída a hospitalidade. Para Lohmann et al. (2013, p. 82), "o transporte é condição sinequa non para a realização de atividades turísticas".

Outro ponto que pode ser destacado pelos alunos consiste em reflexões críticas sobre o papel da gestão pública na resolução do problema, tendo em vista que ao poder público cabe a fiscalização e regulamentação da mobilidade urbana. Fato esse que repercute nas falas dos personagens do caso.

\section{3ª) Qual a importância da mobilidade urbana para o turismo?}

Ao adentrar na destinação, o turista requer mobilidade intradestino, seja para se locomover do terminal aeroportuário para o hotel, seja para acessar os locais de interesse turístico (hotéis, restaurantes, centros de compras e etc). 0 visitante utiliza serviços de transporte público e os específicos para turismo para acessar seus destinos (Lohmann et al., 2013). Assim, a utilização dos serviços de transportes deve ser pensada e planejada a fim de evitar sobrecarga no sistema de transporte local, causando problemas de mobilidade para a população residente e visitante, tanto de ordem logística quanto financeira.

Para o turismo, os meios de transporte são essenciais. Numa perspectiva do desenvolvimento regional do turismo, a logística de transportes é fundamental na atividade turística, pois é responsável pela circulação; o acesso do turista até o local turístico (receptor). Para Lopes Júnior (2002, p. 180), "no processo de crescimento econômico e de integração do território, o setor de transportes é essencial assim como também para o desenvolvimento econômico de regiões, municípios e até mesmo para prática do turismo.". Nesse sentido, o transporte é um componente fundamental da atividade turística.

Cada modalidade de transporte tem sua forma de trabalhar e possui valores diferentes de níveis de serviço, onde o turista quer vir à cidade e se locomover gastando menos no transporte, com qualidade no serviço, e ao mesmo tempo, quer poder usufruir e gastar mais em outras atividades. 0 conflito gerado pelas prestadoras de serviços é devido ao custo entre eles, que chega a ter uma diferença de $70 \%$, bem como em relação ao tempo de chegada, horários e padrões dos serviços oferecidos.

A urgência na solução do problema, por parte do poder público, é necessária por que o destino passa a ter sua imagem afetada. Principalmente, pelos tempos fluídos da contemporaneidade; os turistas planejam suas viagens, muitas vezes, do início ao fim na Internet, pois buscam por comentários anteriores sobre os locais que anseiam conhecer, e relatam suas experiências de viagem nas redes sociais ainda no destino e/ou ao regressarem à cidade de origem.

4모 Debata sobre a importância de uma política pública que vise uma melhor infraestrutura de acesso (vias públicas) ao aeroporto.

Em se tratando da política de mobilidade urbana, é importante o envolvimento de todos os 
municípios afetados pelo problema da mobilidade na região. Numa tentativa de sensibilizar os diversos atores públicos e privados envolvidos, o dilema do caso poderia ser colocado em pauta pelo gestor de turismo do munícipio de São Gonçalo nas reuniões das instâncias de governança regional: o Polo Costa das Dunas.

Devido à cidade de Natal ser um dos pontos turísticos mais procurados no Nordeste, por possuir praias belas, lagoas e lugares exóticos, a gestão pública deve elaborar um plano para melhorar o acesso que interliga estes locais de destino com o aeroporto, pois se percebe que há uma perda de tempo muito grande na locomoção entre estes lugares. As obras de acesso ao aeroporto, bem como as relacionadas à melhoria do anel viário metropolitano de Natal a serem realizadas pelo governo do estado do RN com recursos federais, visam reduzir a sobrecarga de veículos longos e pesados no perímetro urbano. (Portal do Governo do RN, 2016). As políticas públicas e os programas de desenvolvimento do turismo são traçados, em geral, tomando como base as políticas públicas de transporte ou seus resultados: em alguns casos são pensados conforme a infraestrutura de transportes já existente e a possibilidade de utilizá-la para o turismo; em outros, parte dos recursos destinados aos programas de desenvolvimento turístico são alocados para construção ou manutenção de vias de acesso e seus equipamentos, quando essa infraestrutura é inexistente ou precária. (Lohmann et al., 2013).

\section{5a) Sendo você o gestor de turismo do município de São Gonçalo do Amarante, o que faria para solucionar esta questão acerca da mobilidade e logística de transportes ao aeroporto?}

Pode-se solicitar aos alunos, o desenvolvimento de um plano de ação, com uma discussão dos problemas, do que deveria ser feito para resolvê-los, além disso, quais entidades seriam responsáveis pela sua execução, contendo ainda um cronograma para o desenvolvimento das propostas. Deve ser solicitado também para que o aluno escolha dois dos problemas de curto prazo e detalhe as ações.

\begin{tabular}{|c|c|c|c|c|c|}
\hline PRINCIPAIS PROBLEMAS & AÇõES & $\begin{array}{l}\text { ENTIDADES } \\
\text { RESPONSÁVEIS }\end{array}$ & $\mathbf{C P}$ & MP & LP \\
\hline \multirow[t]{3}{*}{$\begin{array}{l}\text { Conflito relativo ao transporte } \\
\text { de passageiros no aeroporto }\end{array}$} & Colocar em pauta nas reuniões do polo & $\begin{array}{l}\text { Prefeitura de São Gonçalo } \\
\text { e Polo Costa das Dunas }\end{array}$ & $\mathrm{X}$ & & \\
\hline & $\begin{array}{l}\text { Elaborar política de mobilidade urbana } \\
\text { em conjunto com as demais cidades da } \\
\text { região metropolitana }\end{array}$ & Prefeitura de São Gonçalo & & & $X$ \\
\hline & $\begin{array}{l}\text { Definição dos papéis de cada prestador } \\
\text { de serviço de transporte de passageiros }\end{array}$ & $\begin{array}{l}\text { Prefeitura de São Gonçalo } \\
\text { e Polo Costa das Dunas }\end{array}$ & & $X$ & \\
\hline $\begin{array}{l}\text { Sinalização durante o percurso } \\
\text { ao aeroporto }\end{array}$ & $\begin{array}{l}\text { Reunião para conseguir recursos do } \\
\text { DNIT }\end{array}$ & $\begin{array}{l}\text { Prefeituras de Natal, São } \\
\text { Gonçalo, Parnamirim, } \\
\text { Macaíba e Ceará-Mirim }\end{array}$ & $\mathrm{X}$ & & \\
\hline \multirow[t]{3}{*}{ Incentivo ao modal rodoviário } & $\begin{array}{l}\text { Elaborar projeto de mobilidade, } \\
\text { pensando na Inclusão de outras linhas } \\
\text { de ônibus até o aeroporto }\end{array}$ & $\begin{array}{l}\text { Prefeitura de São Gonçalo } \\
\text { e região metropolitana }\end{array}$ & & $\mathrm{X}$ & \\
\hline & $\begin{array}{l}\text { Implantação de ônibus executivo } \\
\text { (frescão) }\end{array}$ & $\begin{array}{l}\text { Prefeitura de São Gonçalo } \\
\text { e Inframérica }\end{array}$ & $\mathrm{X}$ & & \\
\hline & Integração do modal ferroviário & $\begin{array}{l}\text { Governo do estado, } \\
\text { Prefeitura de São Gonçalo } \\
\text { e CBTU }\end{array}$ & & & $\mathrm{X}$ \\
\hline Abrigos de passageiros & $\begin{array}{l}\text { Elaboração de projeto de abrigos de } \\
\text { passageiros padronizados para a região } \\
\text { metropolitana }\end{array}$ & $\begin{array}{l}\text { Prefeitura de São Gonçalo } \\
\text { e Polo Costa das Dunas }\end{array}$ & & $\mathrm{X}$ & \\
\hline Obras de acesso inacabadas & $\begin{array}{l}\text { Colocar o assunto em pauta em reunião } \\
\text { do Polo Costa das Dunas }\end{array}$ & $\begin{array}{l}\text { Prefeitura de São Gonçalo } \\
\text { e Polo Costa das Dunas }\end{array}$ & $\mathrm{X}$ & & \\
\hline $\begin{array}{l}\text { Problema de qualidade no } \\
\text { serviço de transporte público }\end{array}$ & $\begin{array}{l}\text { Condicionar a renovação da concessão } \\
\text { de ônibus do município de São Gonçalo } \\
\text { à melhoria dos veículos em relação à } \\
\text { acessibilidade e conforto para o } \\
\text { transporte de passageiros. }\end{array}$ & Prefeitura de São Gonçalo & $\mathrm{X}$ & & \\
\hline
\end{tabular}

Tabela 01- Principais problemas e ações sugeridas em curto, médio e longo prazo.

Fonte: Elaboração própria, 2017.

\section{Notas}

CP - Curto prazo; ML - Médio prazo; LP - Longo Prazo. 


\section{Referências}

AgoraRN. (26 de Novembro de 2016). Polícia Militar e DER apreendem Ubers que buscam passageiros no aeroporto Aluízio Alves. Fonte: AgoraRN: http://agorarn.com.br/policia/policia-militar-e-der-realizamapreensao-de-ubers-que-buscam-passageiros-no-aeroporto-aluizio-alves/.

Calixto, A. (09 de Dezembro de 2016). Fiscalização do DER no aeroporto de São Gonçalo. (I. Marcolino, Entrevistador).

Costa, G. (08 de Dezembro de 2016). Serviço de van oferecido no aeroporto. (A. Cacho, Entrevistador). IBGE. (04 de setembro de 2018). Pesquisa de Serviço de Hospedagem. Fonte: IBGE:

https://cidades.ibge.gov.br/brasil/rn/natal/pesquisa/34/62873?ano=2011.

Inframérica. (22 de novembro de 2016). Estatísticas. Fonte: Inframérica: http://www.natal.aero/br/oaeroporto/estatisticas./

Lohmann, G. (2013). Transportes e destinos turísticos: planejamento e gestão. Rio de Janeiro: Elsevier. Lopes Júnior, W. M. (2012). Turismo, transportes e regionalização: considerações geográficas. RA'EGA: $O$ Espaço Geográfico em Análise. 26. 170-193.

Macedo, P. R. (17 de Janeiro de 2017). Mobilidade no aeroporto Aluísio Alves. (A. Cacho, Entrevistador).

Ministério do Planejamento. (27 de dezembro de 2016). Acesso ao novo aeroporto de São Gonçalo do Amarante.

Fonte: Ministério do Planejamento: http://www.pac.gov.br/obra/35630.

Novo Notícias. (19 de maio de 2017). Motorista do Uber é agredido no Aeroporto de São Gonçalo.Fonte: Novo Notícias: https://www.novonoticias.com/cotidiano/video-motorista-do-uber-e-agredido-no-aeroporto-de-saogoncalo.

O Natalense. (2017). Polícia Militar e DER apreendem Ubers que buscam passageiros no aeroporto Aluízio Alves Fonte: O Natalense: http://www.onatalense.com.br/policia-militar-der-apreendem-ubers-buscam-passageirosno-aeroporto-aluizio-alves/

Observatório das Metrópoles. (13 de dezembro de 2016). Livro Mobilidade Urbana no Brasil. Fonte:

Observatório das Metrópoles: http://observatoriodasmetropoles.net.br/wp/livro-mobilidade-urbana-nobrasil/.

Portal do Governo do RN. (02 de fevereiro de 2016). Governador libera viaduto e visita obras de trecho sul. Fonte: Portal do Governo do RN:

http://www.gabinetecivil.rn.gov.br/Conteudo.asp?TRAN=ITEM\&TARG=94974\&ACT=null\&PAGE=null\&PARM=n ull\&LBL=NOT\%C3\%8DCIA.

Simon, S., Gastal, S., Santos, M. M.C. (2014). Mobilidade e turismo: hospitalidade no transporte coletivo em Caxias do Sul/RS. Revista Brasileira de Pesquisa em Turismo. São Paulo, 8, 3, 552-567.

Tribuna do Norte. (01 de abril de 2017). Uber: motoristas insultam taxistas no Aeroporto Aluísio Alves. Fonte: Tribuna do Norte: http://www.tribunadonorte.com.br/noticia/uber-motoristas-insultam-taxistas-no-aeroportoalua-zio-alves/375867.

Vasconcellos, E. (2017). Idas e vindas: passado, presente e futuro da mobilidade urbana no Brasil. (J. Rodrigues; J. Legroux, entrevistador). 